\title{
Technique for Robotic Ivor Lewis Esophagectomy with 6-cm Linear Stapled Side-to-Side Anastomosis
}

\author{
June S. Peng, MD, Steven J. Nurkin, MD, Steven N. Hochwald, MD, and Moshim Kukar, MD \\ Department of Surgical Oncology, Roswell Park Comprehensive Cancer Center, Buffalo, NY
}

Minimally invasive esophageal resections for esophageal cancer have been shown to decrease postoperative complications compared with open esophagectomy without compromising oncologic outcomes, including in randomized trials comparing open with laparoscopic/ thoracosopic, ${ }^{1}$ robotic, ${ }^{2}$ and hybrid ${ }^{3}$ approaches.

In the accompanying video, we present our technique for robotic Ivor Lewis esophagectomy. We demonstrate a stapled side-to-side anastomosis, which is associated with a lower leak rate compared with a cervical anastomosis in our experience. ${ }^{4}$ Potential benefits of this technique compared with a stapled end-to-end anastomosis (EEA) include a larger anastomotic diameter and improved vascular supply. The robotic platform allows for completion of the operation from the console with use of the robotic linear stapler and intracorporeal suturing.

\section{VIDEO}

The da Vinci Xi robotic platform (Intuitive Surgical, Sunnyvale, CA) is used. Dissection begins in the abdomen with division of the gastrocolic ligament, preserving the right gastroepiploic vessels. The transverse mesocolon is

Presented at the Society for Surgical Oncology 2019 Annual Cancer Symposium May 27-30, 2019 in San Diego, CA.

Electronic supplementary material The online version of this article (https://doi.org/10.1245/s10434-019-07933-4) contains supplementary material, which is available to authorized users.

(C) Society of Surgical Oncology 2019

First Received: 29 June 2019;

Published Online: 4 December 2019

M. Kukar, MD

e-mail: moshim.kukar@roswellpark.org dissected from the stomach and duodenum, and the duodenum is mobilized. The right gastric artery is divided, followed by the left gastric vein and artery. The gastric conduit is fashioned using loads of a $60-\mathrm{mm}$ robotic stapler. The patient is then repositioned into left lateral decubitus position. The thoracic esophagus is dissected free circumferentially. The azygous vein is divided, and the esophagus is divided. After the specimen is extracted and the margin is confirmed negative, a 60 - $\mathrm{mm}$ side-to-side esophagogastrostomy is created and the common channel is closed using a stapling technique.

DISCLOSURES The authors declare no conflicts of interest.

\section{REFERENCES}

1. Biere SS, van Berge Henegouwen MI, Maas KW, et al. Minimally invasive versus open oesophagectomy for patients with oesophageal cancer: a multicentre, open-label, randomised controlled trial. Lancet. 2012;379(9829):1887-1892.

2. van der Sluis PC, van der Horst S, May AM, et al. Robot-assisted minimally invasive thoraco-laparoscopic esophagectomy versus open transthoracic esophagectomy for resectable esophageal cancer: a randomized controlled trial. Ann Surg. 2019;269(4): 621-630.

3. Mariette C, Markar SR, Dabakuyo-Yonli TS, et al. Hybrid minimally invasive esophagectomy for esophageal cancer. $N$ Engl J Med. 2019;380(2):152-162.

4. Ben-David K, Tuttle R, Kukar M, Rossidis G, Hochwald SN. Minimally invasive esophagectomy utilizing a stapled side-to-side anastomosis is safe in the Western patient population. Ann Surg Oncol. 2016;23(9):3056-3062.

Publisher's Note Springer Nature remains neutral with regard to jurisdictional claims in published maps and institutional affiliations. 